\title{
Vibrotactile temporal summation for threshold and suprathreshold levels of stimulation
}

\author{
GEORGE A. GESCHEIDER and JOHN M. JOELSON \\ Hamilton College, Clinton, New York
}

\begin{abstract}
Threshold measurement and matching procedures were used to determine the amount of temporal summation at threshold and suprathreshold levels of vibrotactile stimulation on the thenar eminence of the hand. The frequency of the stimulus was $25,40,80$, or $200 \mathrm{~Hz}$. At $25 \mathrm{~Hz}$, temporal summation was absent at all intensity levels. Considerable amounts of temporal summation were observed for $80-$ and $200-\mathrm{Hz}$ stimuli, although the effects decreased as a function of intensity. At $40 \mathrm{~Hz}$, no temporal summation was observed at threshold, but above threshold, a small amount was observed at all intensity levels. The results support a duplex model of mechanoreception in which one of two receptor systems exhibits temporal summation.
\end{abstract}

Considerable psychophysical research on tactile sensitivity has been directed at determining how physical parameters of a vibrotactile stimulus affect detection thresholds (for reviews, see Gescheider, 1976, and Verrillo, 1968). In agreement with earlier findings of other investigators (Békésy, 1939; Gilmer, 1935; Hugony, 1935; Sherrick, 1953), Verrillo (1963) found vibrotactile thresholds on the hand to be a U-shaped function of the frequency of the stimulus. In addition, Verrillo showed that at low frequencies the threshold curve was high and flat. The break point at which the curve changed from flat to $U$ shaped depended on the size of the contactor used to deliver the stimulus to the skin. Thresholds along the U-shaped portion of the curve decreased as conductor size was increased, whereas thresholds along the flat portion of the curve were the same for different contactor sizes. Verrillo concluded that two different types of cutaneous receptors mediated the detection of vibration. At low frequencies, the receptor has a flat frequency response and is not capable of spatial summation. On the other hand, at frequencies within the U-shaped portion of the threshold curve, another receptor, one capable of spatial summation, mediates the psychophysical threshold. Verrillo identified the Pacinian corpuscle as the receptor most likely to mediate thresholds within the U-shaped portion of the curve. Since that time, it has been conclusively demonstrated through electrophysical experiments that both Pacinian and nonPacinian receptors mediate the detection of vibration (e.g., Talbot, Darian-Smith, Kornhuber, \& Mountcastle, 1968).

Much of the recent research on this problem has consisted of attempts to identify other properties of

The author's mailing address is: Department of Psychology, Hamilton College, Clinton, New York 13323. the two neural systems that mediate the detection of vibration. One of these properties, which is thought to distinguish the Pacinian from the non-Pacinian system, is temporal summation-the integration of energy over time by a sensory system. The results of several studies suggest that the Pacinian, but not the non-Pacinian, system is capable of temporal summation. Verrillo (1965), using stimulus frequencies of 100,250 , and $500 \mathrm{~Hz}$ and a contactor size of $2.9 \mathrm{~cm}^{2}$, found that thresholds decreased as a function of stimulus duration, precisely as predicted from Zwislocki's (1960) theory of temporal summation. For contactor sizes of .08 and $.05 \mathrm{~cm}^{2}$, however, the shift in threshold as a function of stimulus duration was less than the predicted amount, and no change in threshold was found for a contactor size of $.02 \mathrm{~cm}^{2}$. Verrillo (1965) accounted for this relation between temporal summation and contactor size in terms of the duplex model of mechanoreception. According to the model, the Pacinian system summates energy over time up to about $1.0 \mathrm{sec}$, whereas the non-Pacinian system does not exhibit temporal summation. At threshold, the summating Pacinian receptors are exclusively engaged by large contactor stimulation. If, however, the contactor is very small, a stimulus of sufficient intensity to excite nonsummating receptors may not exceed the threshold of the Pacinian system. Additional support for Verrillo's (1965) interpretation of vibrotactile temporal summation was obtained by Gescheider (1976), who reported that when contactor size was $3.0 \mathrm{~cm}^{2}$, Zwislocki's theory of temporal summation accurately predicted the data for the detection of a $200 \mathrm{~Hz}$ stimulus of variable duration. On the other hand, the psychophysical threshold for the detection of a $30-\mathrm{Hz}$ stimulus remained constant as stimulus duration was changed. This result, obtained with a $30-\mathrm{Hz}$ stimulus, was the same as that obtained with a very small $.02-\mathrm{cm}^{2}$ contactor 
(Verrillo, 1965) and with a $2.9-\mathrm{cm}^{2}$ contactor on the dorsal surface of the tongue (Verrillo, 1968). Since the dorsal surface of the tongue contains no Pacinian corpuscles, it is consistent with the duplex model that the psychophysical threshold for stimulation of this tissue is independent of stimulus duration. It seems that whenever conditions are such that Pacinian corpuscles are not stimulated, the remaining system is insensitive to changes in stimulus duration as well as in frequency and contactor size, whereas thresholds mediated by Pacinian corpuscles are frequency dependent and exhibit spatial and temporal summation.

Green (1976), however, reported results on temporal summation that are not in clear agreement with this hypothesis. In his study, detection thresholds were measured for stimuli of varied duration delivered through a $1.32-\mathrm{cm}^{2}$ contactor to the thenar eminence. The amount of temporal summation for detecting $160-\mathrm{Hz}$ stimuli was comparable to that reported by Gescheider (1976) and Verrillo (1965) when they used high-frequency stimuli delivered through large contactors. However, contrary to the hypothesis that the nonPacinian system does not integrate energy over time was the finding of a small, but significant, amount of temporal summation when the frequency of the test stimulus was $25 \mathrm{~Hz}$. Green interpreted his results to mean either that the nonPacinian system is capable of temporal summation or that in his experiment the detection of lowfrequency stimuli was mediated by both a summating Pacinian system and a nonsummating non-Pacinian system. Green seems to favor the second of these interpretations and accounts for temporal summation at $25 \mathrm{~Hz}$ by assuming that both Pacinian and non-Pacinian receptors contribute to sensation at threshold and that as stimulus duration increases, the contribution of the Pacinian system increases.

It should be possible to study the contribution of Pacinian and non-Pacinian systems to temporal summation functions by examining how the sensation magnitude of suprathreshold stimuli changes as the duration of stimuli of varied frequency is changed. In the present study, temporal summation was examined at stimulus intensities ranging from the threshold to $40 \mathrm{~dB}$ above threshold for frequencies of $25,40,80$, and $200 \mathrm{~Hz}$. A matching procedure was used to determine the intensities that result in equal sensation magnitude when stimulus duration is varied from 30 to $1000 \mathrm{msec}$.

\section{METHOD}

\section{Subjects}

Three male subjects, two 20-year-old college students and one 39-year-old faculty member, served as subjects. The subjects had extensive experience in making psychophysical judgments of vibrotactile stimuli.

\section{Apparatus}

Sinusoidal vibratory stimuli were delivered to the thenar eminence of the subject's hand. The $3.0-\mathrm{cm}^{2}$ contactor on a Ling 203 vibrator was adjusted at the start of each experimental session to make a .5-mm depression in the skin surface under the contactor. Vibration of the skin was confined to the region of the contactor by using a rigid surround upon which the subject rested his hand. Between the surround and the contactor was a $1.0-\mathrm{mm}$ gap. Vibration amplitude was measured with a calibrated accelerometer mounted on the moving element of the vibrator, and all measurements were expressed in decibels re $1.0-\mu$ peak displacement of the contactor. All measurements were made while the subject's hand was in the test position.

The subject and the vibrator assembly were located in a booth to provide isolation from vibrations of the building and sounds in the laboratory. The sound of the vibrator was masked by a continuous, narrow-band noise centered at the frequency of the vibratory stimuli.

Electrical signals were delivered to the vibrator through two separate channels. Signals in each channel generated by an audiooscillator were passed through two electronic switches, which were adjusted to provide a 10 -msec rise-decay time for each stimulus. Stimulus duration was regulated by applying a $10-\mathrm{V} \mathrm{dc}$ pulse of variable duration to the triggering circuit of the electronic switch. The duration of the stimulus was measured at the halfpower point. The intensity of signals was controlled by the experimenter by decade attenuators in each channel. The duration was variable in one channel and was held constant at $1,000 \mathrm{msec}$ in the other. The subject was able to adjust the intensity of the stimuli of variable duration by controlling a Békésy recording attenuator.

\section{Procedure}

The subjects tracked their thresholds for detecting vibrotactile stimuli of $25,40,80$, and $200 \mathrm{~Hz}$ delivered for durations of 30 , so, 100,200,300,600, and 1,000 msec. Thresholds were measured by the Békésy tracking method. The subjects controlled a hand switch to maintain stimulus intensity near threshold. The time interval between stimuli was $1,000 \mathrm{msec}$. When the switch was pressed, stimulus intensity decreased at a rate of $1.0 \mathrm{~dB} / \mathrm{sec}$, and when the subjects released the switch, the intensity increased at the same rate. The increases and decreases in intensity that resulted from the subjects' tracking over a period of $2.0-4.0 \mathrm{~min}$ were recorded on the recording attenuator. Thresholds were derived by fitting a horizontal line through the middle of the subjects' records. The voltage output of the accelerometer was measured for this value and converted to peak displacement of the vibrator in decibels re $1.0 \mu$. Three thresholds for each combination of stimulus frequency and duration were measured for each subject.

In the matching procedure, two stimuli separated by $1,000 \mathrm{msec}$ were presented every $5 \mathrm{sec}$. The duration of the first stimulus was $1,000 \mathrm{msec}$ and was fixed in intensity at $5,10,20,30$, or $40 \mathrm{~dB}$ above absolute threshold. The duration of the second stimulus was $30,50,100,200,300,600$, or $1,000 \mathrm{msec}$. The subjects' task was to equate the sensation magnitudes of the two stimuli by adjusting the intensity of the second stimulus. On each trial, the subjects, using a bracketing procedure, adjusted the intensity of the second stimulus by closing a switch to decrease intensity and by releasing it to increase intensity. When the subjects were satisfied with the match, the intensity of the second stimulus was measured. Matching data were obtained for all combinations of stimulus duration, intensity, and frequency.

\section{RESULTS AND DISCUSSION}

Mean thresholds for the detection of vibration of varying duration are plotted as functions of fre- 
quency in Figure 1. For each stimulus duration, the data follow the typical bisegmented threshold function (e.g., Gescheider, 1976; Verrillo, 1963). The low-frequency branch of the function is flat, and the high-frequency branch has a negative slope of approximately $-12 \mathrm{~dB} /$ octave. Presumably, the lowfrequency branch is mediated by non-Pacinian corpuscles that have neural thresholds that at body temperature are known to decrease at a rate of $12 \mathrm{~dB} /$ octave (Bolanowski, 1981). The dashed lines in Figure 1 represent an extrapolation of the neural thresholds of the Pacinian and non-Pacinian systems from the psychophysical data.

At frequencies of 25 and $40 \mathrm{~Hz}$, thresholds were approximately the same for all stimulus durations. This finding agrees with the results of Gescheider (1976), who reported that thresholds for the detection of $25-\mathrm{Hz}$ vibration were not influenced by changes in stimulus duration, and is consistent with the hypothesis that the non-Pacinian system is incapable of temporal summation. At frequencies of $\mathbf{8 0}$ and $200 \mathrm{~Hz}$, thresholds decrease as stimulus duration increases, in accordance with Zwislocki's (1960) theory of temporal summation. The data points in Figure 1 for these frequencies were fitted with linear functions having slopes of $-12 \mathrm{~dB} /$ octave, characteristic of Pacinian corpuscles. The functions for different stimulus durations are separated by distances predicted by Zwislocki's temporal-summation theory. The close fit of the data points to the predicted functions strongly supports the hypothesis that the Pacinian system is capable of temporal summation.
In Figure 2, the threshold data are plotted as a function of stimulus duration for each of the four frequencies. The filled circles are the results of the present experiment, and the open circles are from Gescheider (1976). The threshold decreased as a function of stimulus duration when the frequency was 80 or $200 \mathrm{~Hz}$ but was nearly constant with changes in stimulus duration when the frequency was 25 or $40 \mathrm{~Hz}$. It is clear that temporal summation occurs for the detection of high- but not lowfrequency stimuli. It is interesting that no temporal summation occurred for the detection of $40-\mathrm{Hz}$ stimuli. It can be seen in Figure 1 that when stimulus duration was $1,000 \mathrm{msec}$, the break point of the function relating threshold to frequency was at $40 \mathrm{~Hz}$. According to the duplex theory, the break point in this function is the frequency at which the Pacinian and non-Pacinian receptor systems have exactly the same thresholds. Reducing the duration of a $40-\mathrm{Hz}$ stimulus should elevate the threshold of the Pacinian system but have no effect on the threshold of the nonPacinian system. Because detection thresholds for all 40-Hz stimuli shorter than 1,000-msec are mediated by non-Pacinian receptors, no temporal summation should occur at this frequency.

Although there is no indication of temporal summation in the detection of $40-\mathrm{Hz}$ stimuli, it can be seen in Figure 2 that at suprathreshold intensities, temporal summation occurs at this frequency. At each sensation level, the intensity needed to keep sensation magnitude constant increased as stimulus duration decreased. Suprathreshold temporal sum-

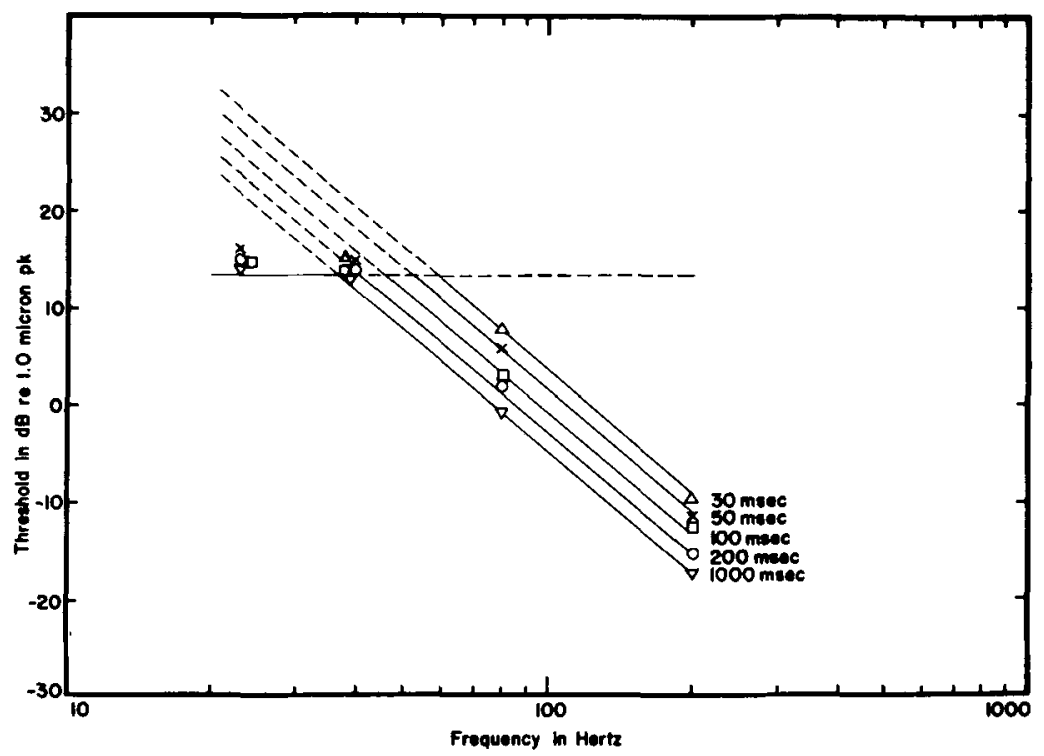

Figure 1. Vibrotactlle thresholds as a function of frequency for five durations of the stimulus. Functions with slopes of $-12 \mathrm{~dB} /$ octave were fitted to the 80 - and $200-\mathrm{Hz}$ data points. The vertical separation of this function was predicted from $Z$ willocid's (1960) theory of temporal summation. The dashed lines are extrapolations of the threaholds of the Pacinian and nonPacinian receptor aystems. 


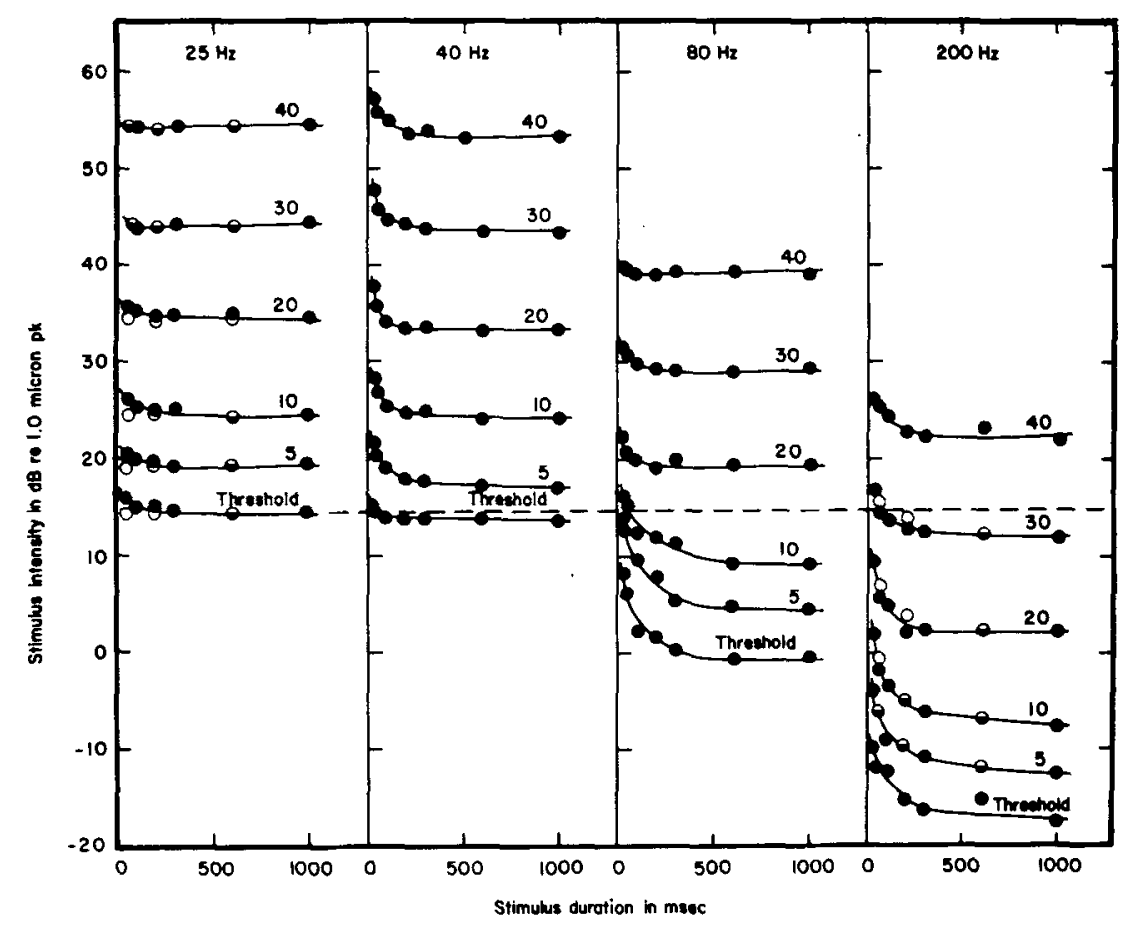

Figure 2. Threshold and equal-senuntion magnitude functions for changes in atimulus duration. Each equal-sensation magnitude function was measured when the censation level of the 1000-muec stimulus was set at some constant value of 5, 10, 20, 30, or $40 \mathrm{~dB}$ SL. Open circles are the values derived from maguitude-estimation data (Geachelder, 1976).

mation at $40 \mathrm{~Hz}$ might be explained in terms of summation of sensory magnitudes of the Pacinian and non-Pacinian systems. There is evidence from psychophysical studies that the sensation magnitude of a stimulus is the sum of the sensation magnitudes of the Pacinian and non-Pacinian systems (Marks, 1979; Verrillo \& Gescheider, 1975). Since the thresholds of the Pacinian and non-Pacinian systems are the same at $40 \mathrm{~Hz}$, the sensory responses of the two systems should be approximately the same for a $1000-\mathrm{msec}$, 40-Hz suprathreshold stimulus and should contribute equally to the total sensation magnitude of the stimulus. As the duration of the stimulus is reduced, however, the contribution of the Pacinian system should decrease, causing a decline in the sensory magnitude of the stimulus. Consequently, to keep sensation magnitude constant, the intensity of the stimulus must be increased as its duration is decreased.

To test the hypothesis of the summation of sensory magnitudes of Pacinian and non-Pacinian systems, the amounts of temporal summation observed in the present study were compared with the amounts calculated from Pacinian and non-Pacinian sensationmagnitude functions. The forms of the sensationmagnitude functions of the Pacinian and non-Pacinian systems were estimated from magnitude estimations of, respectively, $250-\mathrm{Hz}$ and $25-\mathrm{Hz}$ stimuli
(Gescheider, 1976) and are presented in Figure 3. At each stimulus frequency, there are sensationmagnitude functions for the Pacinian system for stimulus durations of 50 and $1,000 \mathrm{msec}$. These two functions were based on magnitude estimations of the sensation magnitudes of 50 - and 1,000-msec stimuli that had a frequency of $250 \mathrm{~Hz}$ (from Gescheider, 1976). The single function for the non-Pacinian system was based on magnitude-estimation functions of $25-\mathrm{Hz}$ stimuli that were identical for 50 - and 1,000 msec stimuli (Gescheider, 1976). At each stimulus frequency used in the present study, the position of each sensation-magnitude function was adjusted to start at the system's absolute thresholds estimated from Figure 1. Since the sensitivity of the non-Pacinian system is thought to be independent of frequency, its sensation-magnitude function always starts at the same stimulus intensity (13.2 dB re 1.0- $\mu$ peak).

An example of how predictions were made of the amount of temporal summation for perception of 1,000- and 50-msec, 40-Hz stimuli is seen in Figure 4. Since the absolute thresholds of the Pacinian and nonPacinian systems are about the same for detecting a 40-Hz, 1,000-msec stimulus (Figure 1), the sensationmagnitude functions of the two systems start at the same intensity for this stimulus (Figure 4). If there 


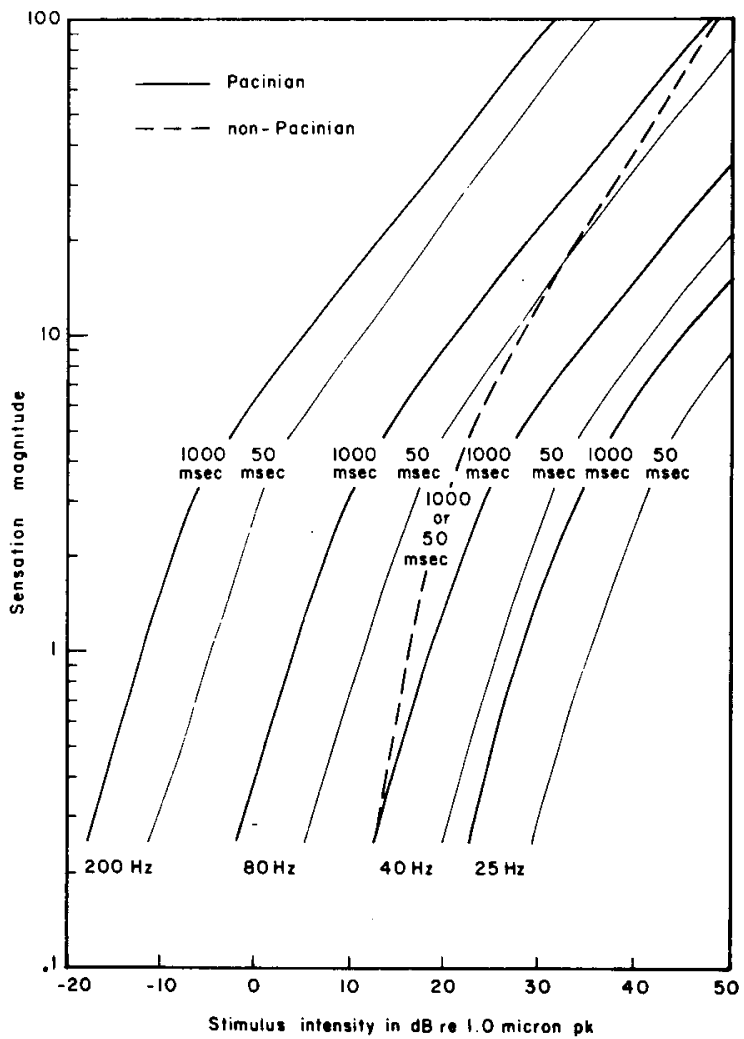

Figure 3. Sensation-magnitude functions for the Pacinian and nonPacinian systems for four stimulus frequencies and two stimulus durations. The forms of the functions were determined by Gescheider (1976), and the starting point for each function was the theoretical threshold of the Pacinian or non-Pacinian system for detecting a 50 - or 1,000-msec stimulus as estimated from Fig. ure 2 of this study.

were no summation of sensory magnitude between the two systems and the Pacinian system alone determined sensory magnitude, the intensities of 50 - and 1,000-msec stimuli matching in sensory magnitude could be predicted directly from the two Pacinian functions. The stimulus intensity values for the 50- and 1,000-msec stimuli resulting in identical sensory magnitude would simply be noted on the abscissa of the function. Under this nonsummation hypothesis, the nonPacinian system would not contribute to the overall sensory magnitude of the stimuli, and the expected differences in intensity for the 50 - and 1,000-msec stimuli would be between 5.0 and $7.5 \mathrm{~dB}$, depending on intensity. The experimentally obtained intensity difference, however, ranged between 2.2 and $3.0 \mathrm{~dB}$. The prediction of the results is not improved by assuming that at $40 \mathrm{~Hz}$ it is the non-Pacinian system that exclusively determines sensation magnitude, because if this were the case, the difference in intensity of the 50- and 1,000-msec stimuli should be $0.0 \mathrm{~dB}$ at all intensity levels.

It appears that without taking into account the summation of sensory magnitude of the two systems, it is not possible to accurately predict sensationmagnitude matches from sensory-magnitude functions. The procedure for predicting sensory-magnitude matches of the 50 - and $1,000-\mathrm{msec}, 40-\mathrm{Hz}$ stimuli from the summation hypothesis was as follows: (1) From Figure 4, the sum of the sensory magnitudes of the Pacinian and non-Pacinian systems was determined for a particular intensity of the stimulus when it was of $1,000-\mathrm{msec}$ duration. For example, at $33.2 \mathrm{~dB}$, the sensation magnitudes of the non-Pacinian system, the Pacinian system, and the sum of the two were 8.0, 18.0, and 26.0, respectively. (2) From Figure 4, the intensity of the $50-\mathrm{msec}$ stimulus at which the sum of the Pacinian and non-Pacinian sensory magnitudes was equal to the sum of the $\mathrm{Pa}$ cinian and non-Pacinian sensory magnitudes of the 1,000-msec stimulus was determined. In our example, the intensity of the $50-\mathrm{msec}$ stimulus would have to be $35.2 \mathrm{~dB}$ in order for the sensation magnitudes

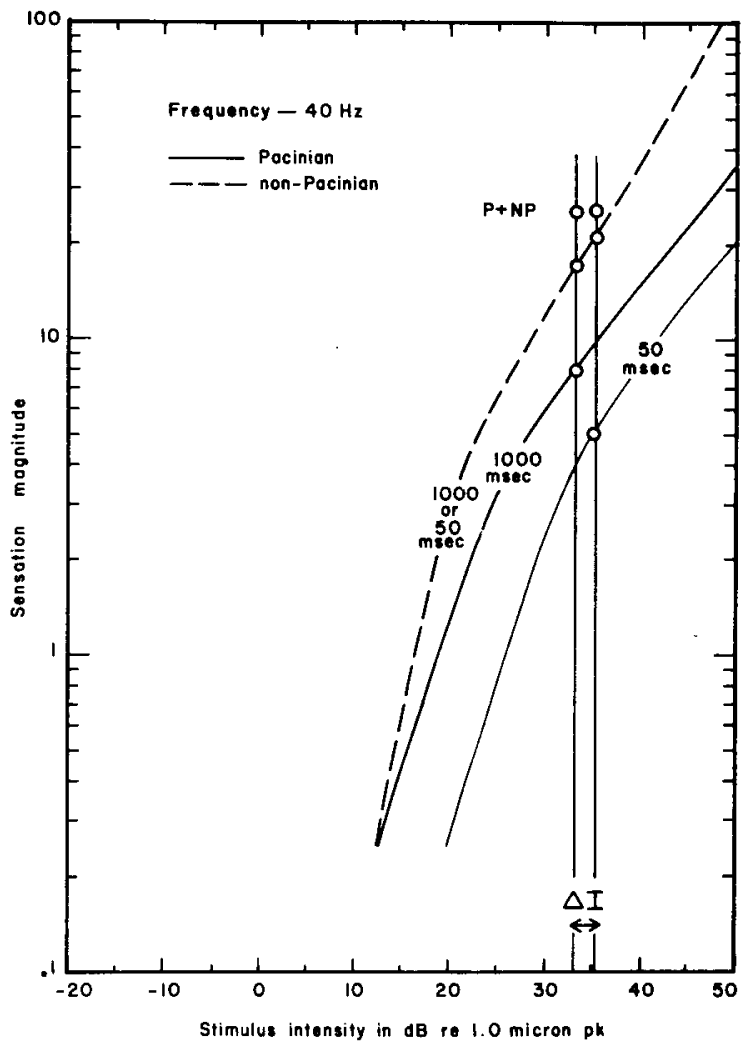

Figure 4. Sensation-magnitude functions for the Pacinian and

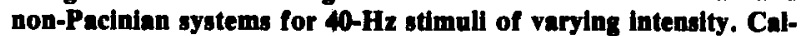
culation of the predicted amount of temporal summation when the 1,000-msec stimulus we $20 \mathrm{~dB}$ SL is lllustrated. At this intensity level, the sums of the senisation magnitudes of the Pacinian and non-Pacinian systems are equal when the intensity of the 50-msec stimulus is $2.0 \mathrm{~dB}$ higher than that of the 1,000 -msec stimulus. Thus, for the two stimull to feel equally intense In a psychophysical matching experiment, the subject would be expected to adjust the intensity of the 50 -msec stimulus to be $2.0 \mathrm{~dB}$ higher than the intensity of the 1,000 -msec stimulus set at $20 \mathrm{~dB}$ SL. 
of the non-Pacinian system (5.0) and the Pacinian system (21.0) to add up to 26.0. The difference in intensity between the 50 - and $1000-\mathrm{msec}$ stimulus was the predicted amount of temporal summation. In our example, the difference would be $35.2 \mathrm{~dB}-$ $33.2 \mathrm{~dB}=2.0 \mathrm{~dB}$. This predicted difference in intensity was compared with the experimentally determined difference in intensity between 50 - and 1,000msec stimuli judged equal in sensation magnitude. In all cases, the obtained and predicted values differed by no more than $1.0 \mathrm{~dB}$ (Figure 5). The average standard error of the mean for differences between 50- and 1,000-msec matches was .54 dB, and therefore the values predicted from the summation hypothesis are well within the limits of experimental error. On the other hand, obtained values and values predicted from the nonsummation hypothesis (dashed curves) differed by as much as $4.5 \mathrm{~dB}$ and hence exceed normal limits of experimental error.

Temporal summation is almost completely absent at any intensity for $25-\mathrm{Hz}$ stimuli. It can be seen in Figure 1 that at $25 \mathrm{~Hz}$ the threshold of the Pacinian system for a $1,000-\mathrm{msec}$ stimulus is about $10 \mathrm{~dB}$ higher than that of the non-Pacinian system. Thus, a $25-\mathrm{Hz}$ stimulus that is more than $10 \mathrm{~dB}$ above the psychophysical threshold should exceed the neural

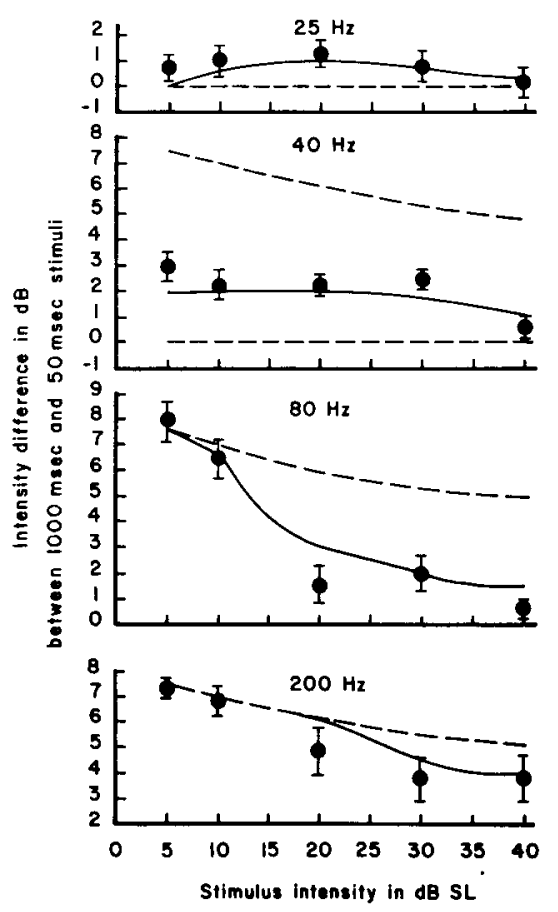

Figure 5. Intensity differences for 1,000- and 50-msec stimuli required for them to feel equally intense. The data points are the means of three subjects, and variability is indicated by atandard. error bars. The solld lines are predictions from the summation hypothesis, and the dashed lines are predictions from the nonsummation hypothesis. threshold of both systems. Assuming that the neural activity of both systems contributes to the perceived magnitude of the stimulus, temporal summation effects due to the activation of the Pacinian system are expected for stimuli above 10-20 dB SL. However, since at $25 \mathrm{~Hz}$ the contribution of the Pacinian system will be much less than that of the non-Pacinian system, temporal summation effects at this frequency should be relatively small. This hypothesis was tested by predicting the amount of temporal summation from the 25-Hz Pacinian and non-Pacinian sensationmagnitude functions of Figure 3. When the Pacinian sensation magnitude of either a 1,000 -msec or 50 msec stimulus is added to the non-Pacinian sensation magnitude, the total sensation magnitude is hardly increased at all, and consequently little temporal summation should be expected at this frequency. Sensation magnitude is determined nearly entirely by the non-Pacinian system, which is thought to be incapable of temporal summation. As can be seen in Figure 5 , the obtained and predicted differences in intensity of the 50- and 1,000-msec stimuli judged equal in sensation magnitude are no greater than $1.0 \mathrm{~dB}$. Thus, the finding of little temporal summation for $25-\mathrm{Hz}$ stimuli is not inconsistent with the hypothesis that the sensation magnitude of suprathreshold stimuli is determined by the summation of the sensation magnitude from the Pacinian and nonPacinian systems.

The relatively small contribution of the Pacinian system to the sensation magnitude of suprathreshold $25-\mathrm{Hz}$ stimuli makes it difficult to understand why spatial summation should occur in judging the sensory magnitude of $25-\mathrm{Hz}$ suprathreshold stimuli (Green \& Craig, 1974; Verrillo, 1974). The presence of spatial summation and the absence of temporal summation in judging the sensory magnitude of lowfrequency suprathreshold vibrotactile stimuli is well established. Both magnitude estimation (Verrillo, 1974) and matching procedures (Green \& Craig, 1974) reveal spatial summation at suprathreshold levels of $25-\mathrm{Hz}$ stimulation. On the other hand, magnitude estimation (Gescheider, 1976) and the matching procedure used in this study reveal little, if any, temporal summation at any intensity level of $25-\mathrm{Hz}$ stimulation. The present results on temporal summation suggest that the contribution of the Pacinian system to the sensation magnitude of a $25-\mathrm{Hz}$ stimulus is too small to account for spatial summation in the perception of suprathreshold $25-\mathrm{Hz}$ stimuli. Perhaps there is suprathreshold spatial summation in the non-Pacinian system.

When the test stimulus was $80 \mathrm{~Hz}$, the amount of temporal summation at $5 \mathrm{~dB}$ SL was the same as at threshold (Figure 2). When the test stimulus was $10 \mathrm{~dB} \mathrm{SL}$, the amount of temporal summation was slightly less than at threshold. At $20 \mathrm{~dB}$ SL or more, 
the amount of summation was substantially reduced. The decrease in temporal summation with increases in stimulus intensity appears to be due to engaging the non-Pacinian receptors at about $13.2 \mathrm{~dB}$ re $1.0-\mu$ peak displacement. The level at which non-Pacinian receptors are activated is represented by the broken line at $13.2 \mathrm{~dB}$ (Figure 2). It is clear that when stimuli are above the non-Pacinian threshold, the amount of temporal summation declines. Presumably, the reduced amount of temporal summation above 13.2 $\mathrm{dB}$ is due to the contribution of non-Pacinian neural activity to the overall sensory magnitude of the stimulus. The measured amounts of temporal summation for 50 - and $1,000-\mathrm{msec}$ stimuli presented in Figure 5 are within $1.0 \mathrm{~dB}$ of the amounts predicted from the hypothesis that the sensory magnitudes of the Pacinian and non-Pacinian systems summates to determine total sensory magnitude. In contrast, the amounts of temporal summation predicted from the nonsummation hypothesis deviate from the measured amounts by as much as $4.2 \mathrm{~dB}$. Additional support for the summation hypothesis comes from the 200-Hz data seen in Figure 2. At this frequency, the threshold of the Pacinian system is approximately $30 \mathrm{~dB}$ below that of the non-Pacinian system and the amount of temporal summation is the same at suprathreshold levels below $30 \mathrm{~dB}$ SL as at threshold. It is only when the threshold of the non-Pacinian system is exceeded by the $30-$ and $40-\mathrm{dB}$ SL stimuli that the amount of temporal summation decreases. These results for the $200-\mathrm{Hz}$ stimulus are in close quantitative agreement with those of Verrillo and Smith (1976), who, by using magnitude estimation, were able to determine intensity levels of $250-\mathrm{Hz}$ vibration necessary to keep sensation magnitude constant as stimulus duration varied.

It can be seen in Figure 5 that the amounts of temporal summation predicted from the summation hyothesis are within $1.0 \mathrm{~dB}$ of the obtained amounts at $30 \mathrm{~dB}$ SL and are within $.7 \mathrm{~dB}$ at $40 \mathrm{~dB}$ SL. Predictions from the nonsummation hypothesis deviate from the data by $2.2 \mathrm{~dB}$ at $30 \mathrm{~dB}$ SL and by $1.3 \mathrm{~dB}$ at $40 \mathrm{~dB} \mathrm{SL}$. When the data were considered for all stimulus frequencies and intensities for which differential predictions had been made, the average difference between predicted and obtained amounts of temporal summation was $.58 \mathrm{~dB}$ and $2.52 \mathrm{~dB}$ for the summation and nonsummation hypotheses, respectively.

The results of our experiment support the following hypotheses: (1) the Pacinian, but not the nonPacinian, system is capable of temporal summation;
(2) the Pacinian system is capable of temporal summation at suprathreshold levels of stimulation; and (3) the sensation magnitude of suprathreshold stimuli is determined by activity in both the Pacinian and non-Pacinian systems.

\section{REFERENCE NOTE}

1. Bolanowski, S. J., Jr. Intensity and frequency characteristics of Pacinian corpuscles (Annual Research Report ISR-S-20). Syracuse, N.Y: Syracuse University, Institute for Sensory Research, 1981.

\section{REFERENCES}

BÉkÉsy, G. von. Über dieVibrationsempfindung. Akustiche Zeitschrift, 1939, 4, 316-334.

GESCHEIDER, G. A. Evidence in support of the duplex theory of mechanoreception. Sensory Processes, 1976, 1, 68-76.

GILMER, B. von H. The measurement of the sensitivity of the skin to mechanical vibration. Journal of General Psychology, 1935, $13,36-61$.

Green, B. G. Vibrotactile temporal summation: Effect of frequency. Sensory Processes, 1976, 1, 138-149.

Green, B. G., \& Craig, J. C. The roles of vibration amplitude and static force in vibrotactile spatial summation. Perception \& Psychophysics, 1974, 16, 503-507.

HuaoNY, A. Über die Empfindung von Schwingungen mittels des Tastsinner. Zeitschrift fur Biologie, 1935, 96, 548-553.

MARKs, L. E. Summation of vibrotactile intensity: An analog to auditory critical bands? Sensory Processes, 1979, 3, 188-203.

Sherrick, C. E. Variables affecting sensitivity of the human skin to mechanical vibration. Journal of Experimental Psychology, 1953, 45, 273-282.

Talbot, W. H., Darian-Smith, I., Kornhuber, H. H., \& Mountcastue, V. B. The sense of flutter-vibration: Comparison of the human capacity with response patterns of mechanoreceptive afferents from the monkey hand. Journal of Neurophysiology, 1968, 31, 301-334.

VERRILLO, R. T. Effect of contactor area on the vibrotactile threshold. Journal of the Acoustical Society of America, 1963, 35, 1962-1966.

VERRILLO, R. T. Temporal summation in vibrotactile sensitivity. Journal of the Acoustical Society of America, 1965, 37, 843-846.

VERRILLo, R. T. A duplex mechanism of mechanoreception. In D. R. Kenshalo (Ed.), The skin senses. Springfield, Ill: Thomas, 1968.

Verrillo, R. T. Vibrotactile intensity scaling at several body sites. In F. A. Geldard (Ed.), Cutaneous communication systems and devices. Austin, Tex: Psychonomic Society, 1974.

Verrillo, R. T., \& Gescheider, G. A. Enhancement and summation in the perception of two successive vibrotactile stimuli. Perception \& Psychophysics, 1975, 18, 128-136.

VerriLlo, R. T., \& SMITh, R. L. Effect of stimulus duration on vibrotactile sensation magnitude. Bulletin of the Psychonomic Society, 1976, 8, 112-114.

ZwisLockI, J. Theory of temporal auditory summation. Journal of the Acoustical Society of America, 1960, 32, 1046-1060.

(Manuscript received August 9, 1982;

revision accepted for publication October 19, 1982.) 